\title{
Parietal kinetic ataxia without proprioceptive deficit
}

\author{
J Ghika, J Bogousslavsky, A Uske, F Regli
}

\begin{abstract}
A patient with acute onset "classic" cerebellar ataxia of the right arm without clinically detectable deep sensory loss is reported, in relation to an acute posterior parietal infarct. Wild back and forth swaying of the arm, giving away, or worsening by suppression of vision were not seen. The lesion involved area 5 , parts of area 7, the angular gyrus, the middle and posterior parieto-occipital gyri, and posterior parts of the superior and middle temporal gyri. The paracentral lobule, commonly thought to be responsible for parietal ataxia, was spared. Thus posterior parietal lesions can mimick cerebellar ataxia, possibly by severing specific projections to the ventrolateral thalamic nuclei. On the basis of previous studies in primates, the superior parietal gyrus may play a major part in the ataxia presented by this patient.
\end{abstract}

$(\mathcal{F}$ Neurol Neurosurg Psychiatry 1995;59:531-533)

Keywords: parietal stroke; cerebellar ataxia

Ataxic hemiparesis can be caused by lesions in the pons, internal capsule, corona radiata, thalamus, and frontal and parietal lobes. ${ }^{1-5}$ Pure hemiataxia has been described associated with lesions in the cerebellum or its pathways, in the thalamus, ${ }^{3}$ internal capsule or corona radiata, ${ }^{2}$ and parietal lobe. ${ }^{6}$ Proprioceptive or sensory ataxia from peripheral nerve ${ }^{7}$ or posterior column involvement ${ }^{8}$ may be difficult to distinguish clinically from cerebellar ataxia, but it generally gets worse if the visual control is suppressed. Parietal ataxia or "pseudocerebellar ataxia", ${ }^{6} 9111$ has been considered as a particular type of proprioceptive ataxia, well described by Critchley" with "decomposition of movement, hypometria and hypermetria, and intention tremor," "swaying movements and falling away of the outstretched hand"; on attempting to touch an object the arm "swayed widely back and forth"; in finger to nose testing, there was "marked cerebellar ataxia", with the limb "rather hypotonic"; "rapidly alternating movements were performed badly", and there was "considerable ataxia on the heel-knee test".
We have been able to study a patient presenting with classic kinetic cerebellar ataxia of the right arm, without clinically detectable deep sensory loss, and a minimal corticospinal deficit, who was found to have a posterior parietal infarct.

\section{Patient history and study}

A 45 year old patient, with a history of recurrent transient ischaemic attacks (two hour right hemianopia in January 1992, transient paraesthesia of the right hand in July 1992 and on 1 March 1993), experienced pronounced clumsiness of the right hand on 6 March 1993 accompanied by a two minute feeling of tingling on the left lower hemiface and a left temporal pulsating headache. These had disappeared except for the clumsiness when he consulted our emergency unit a few hours later.

On physical examination, a minimal slow pronator drift, no weakness, but decreased fine motility and hypotonia were noted on the right upper limb. On the finger to nose test, there was hypermetria with both undershooting and overshooting of the target index finger, asynergia and dyschronometria, uncontrolled rebound, and dysdiadochokinesia. Rhythmic movements of the right hand were grossly abnormal, and the patient was unable to clap loudly using the right hand and left palm. All these tests were no worse with the eyes closed, and entirely normal on the left side. Slow distal motility with an equivocal plantar response without ataxia were the only findings on the right lower limb. No static ataxia, ataxic gait, dysarthria, or ataxic or abnormal eye movements were noted. On careful repetitive examinations, there was no abnormality in any epicritic, protopathic, or discriminative sensory modality, and no sensory extinction, neglect, or allaesthesia on the right hemibody. Visual fields on Goldmann perimetry showed minimal lower quadrantanopia. Sensory evoked potentials from both upper and lower limbs were normal on both sides. Neuropsychological examination showed only some difficulty in programming and decreased incitation for speech.

On day 4, CT showed a corticosubcortical parietal lesion on the left side, hyperintense with contrast, and there was a left posterior 
Reconstruction of the MRI lesions showing involvement of the superior parietal gyrus

$(A, B, C, D, H, I)$, the angular gyrus $(A, B, E$

$F)$, the parieto-occipital gyrus $(D, E, F)$, posterior parts of the superior and medium temporal gyri

$(E, F, G)$, and the inferior parietal gyrus $(E, F, G)$.

The paracentral lobule and the primary sensory areas in the postcentral gyrus are not involved.

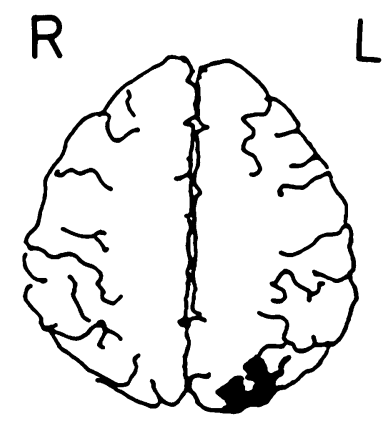

A
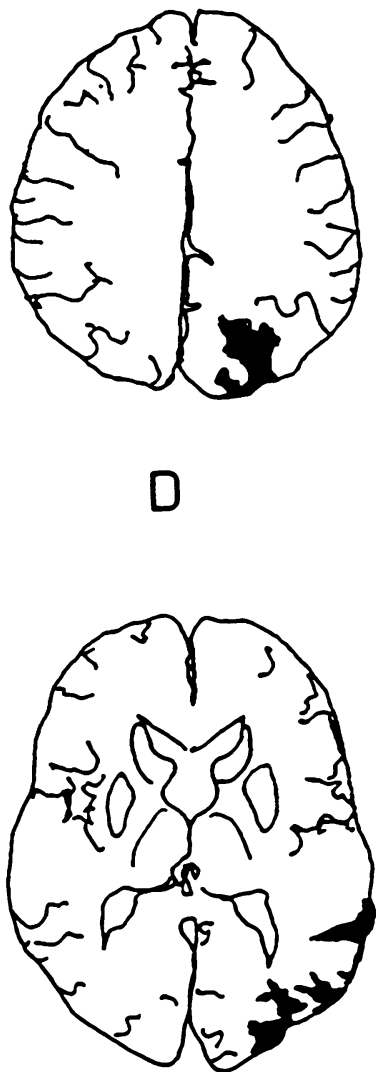

G

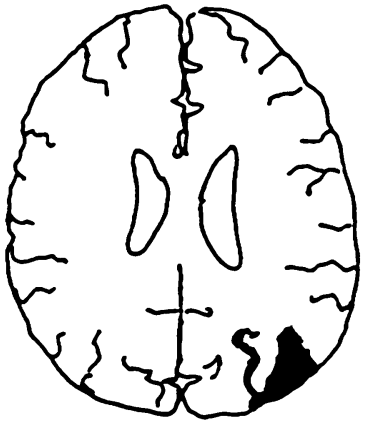

E

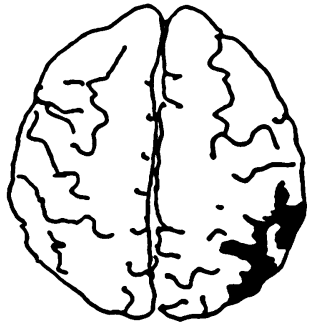

B

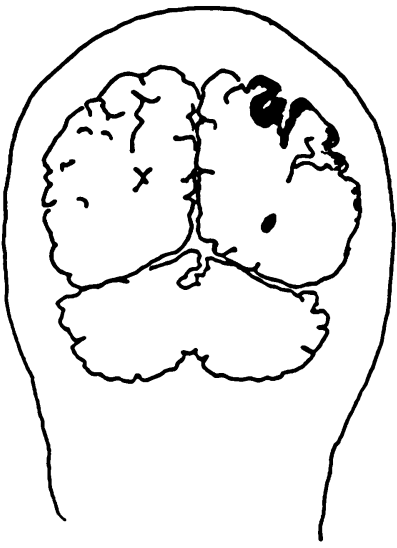

H

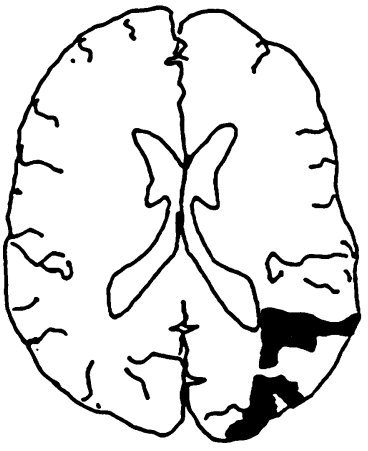

F

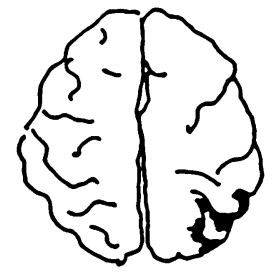

C

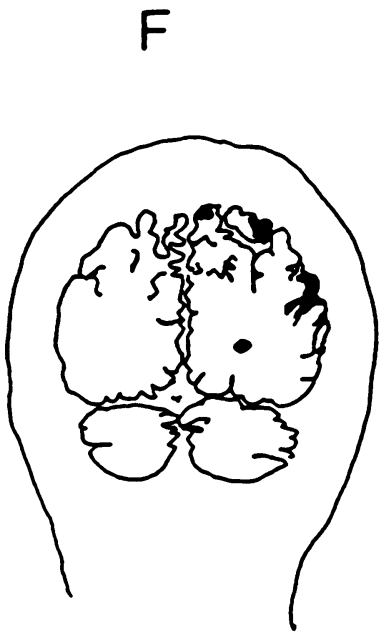

1 temporal arachnoid cyst. Brain MRI on day 6 showed an increased signal in parietal vascular border zones involving most of the superior and parts of the inferior parietal gyri, the angular supramarginal, anterior and posterior temporoparietal gyri, and the upper and posterior regions of the superior and medial temporal gyri and their underlying white matter; the paracentral lobule and inferior parietal gyri were preserved (figure). MR angiography and conventional angiography showed a $70 \%$ stenosis of the right internal carotid artery at the carotid syphon. No lesion or atrophy could be seen in the cerebellum or its pathways in the brainstem, in the thalamic nuclei, or elsewhere in the white matter. Echocardiography, ECG, and analysis of CSF were all normal. No follow up could be obtained.

\section{Discussion}

Parietal ataxia is generally considered to result from the loss of proprioceptive feedback inputs interfering with the smooth execution of motor functions. The clumsiness can be increased by suppression of vision, motions can be disrupted by wild, uncorrected oscillations and giving way of the limb, which makes a clearly recognisable clinical picture at bedside examination.

Here we describe an entirely different clinical presentation; our patient showed all the clinical features of an acute classic cerebellar kinetic ataxia of the right upper limb, without deep sensory loss. This was associated with a posterior, probably watershed, parietal infarct, involving the superior and parts of the inferior parietal gyri, but preserving the paracentral lobule supposedly responsible for 
parietal ataxia. No lesion was seen in the cerebellum, brainstem, or in the frontal lobe in any reconstructions and thin slices of the MRI.

This clinical picture hardly fits with ataxic hemiparesis, occasionally described with parietal lesions, because the lower limb is generally more severely involved and the motor deficit is more prominent. ${ }^{2}$ The absence of the typical axial and postural features and of any abnormal signal in the frontal lobes rules out frontal ataxia. ${ }^{12}$ Proprioceptive ataxia $^{78}$ cannot be considered as there was no positional sense deficit detectable by detailed physical examination and sensory evoked potentials, and no worsening of the ataxia with the eyes closed.

We think that this unique case makes an important contribution to our understanding of parietal sensorimotor integration, because it points to a strategic location for ataxia independently of postural loss in the parietal lobe. In primates, the equivalent of area 5 of humans is the main parietal area to project to the ventrolateral nucleus of the thalamus, in the exact same region which receives fibres from the cerebellum and the motor cortex. ${ }^{13-15}$ Moreover, through the pontine nuclei, a cerebellothalamoparietal pathway has been described which could account for the cerebellar ataxia presented by our patient. ${ }^{15}$ There was little involvement of the inferior parietal gyrus (area 7), supposedly responsible for visually guided movements, and there was no visuomotor ataxia. ${ }^{16}$ The paracentral lobule, considered as responsible for the "pseudocerebellar ataxic parietal syndrome", $91017-20$ was clearly not involved in our patient. This shows that proprioceptive deficits are not necessary for parietal ataxia, but when added, the motions take a more uncontrolled and bizarre expression, typical of the syndrome described by Critchley, ${ }^{11}$ with "wild large oscillations", "falling" and "swaying away" and "back and forth" of the outstretched arm, the position of which is uncontrolled and sometimes even forgotten. These features could be perhaps specific for the paracentral lobule. Other findings encountered in patients with posterior parietal lesions, such as complex sensory deficits, difficulty with precise grip, manipulation and exploration of objects, apraxia, difficulty in copying meaningful and non-meaningful gestures of the hand, dystonia, or avoiding responses were not seen. ${ }^{2122}$ The most anterior lesion on MRI in our patient was in the anterior temporal gyrus, not far from the sensory representation of the hand, which may explain the transient paraesthesia that the patient reported before ataxia, but primary sensory areas were not involved.

In conclusion, patients with posterior parietal lesions can present with classic cerebellar kinetic ataxia without positional loss. Our case could be explained by the lesion of a specific projection of the parietal lobe into the cerebellothalamic pathways, probably from area 5 , as suspected in primates, ${ }^{13} 15$ separated from the proprioceptive elementary and complex projection areas, with resulting cerebellar-like ataxia without sensory loss. This represents a new clinical picture.

1 Fisher CM, Cole M. Homolateral ataxia and crural paresis, a vascular syndrome. $\mathcal{F}$ Neurol Neurosurg Psychiatry, 1965;28:48-55.

2 Moulin T, Bogousslavsky J, Chopard JL, et al. Vascular ataxic hemiparesis: a re-evaluation. $\mathcal{F}$ Neurol Neurosurg Psychiatry 1995;58:422-7.

3 Melo TP, Bogousslavsky J, Moulin T, Nader J, Regli F. Thalamic ataxia. F Neurol 1990;21:24-33.

4 Nicolesco J, Cretu V, Demetresco L. Syndrome de l'artère cérébrale antérieure. Monoplégie crurale droite avec symptomatologie cérébelleuse prépondérante. Bulletin de la Societe Médicale de Hôpitaux di Bucarest 1920;10: 247-50.

5 Yagnik PM, Dhaduk V, Huen L. Parietal ataxic hemiparesis. Eur Neurol 1988;28:164-6.

6 Gerebetzoff MA. Le problème de la localisation et des ataxies corticales comme conclusion à des recherches anatomo-expérimentales. fournal Belge di Neurologie et Psychiatrie 1938;38:108-32.

7 Dalakas M. Chronic idiopathic ataxic neuropathy. Ann Neurol 1986;19:545-54.

8 Hainline B, Tuszynski MH, Posner JB. Ataxia in epidural cord compression. Neurology 1992:42:2193-5.

9 André Thomas, Lévy-Landry $M$. Monoplégie pure du membre supérieur, motrice et sensitive dissociée. Distribution pseudo-radicualire des troubles de la sensibilité. Rev Neurol 1914;1:307-10.

10 Claude $\mathrm{H}$, Lhermitte J. Les paralysies cerebello-spasmodiques et ataxo-cérébello-spasmodiques consécutives aux lésions bilatérales des lobules paracentraux par projectile de guerre. Bulletin de la Societé Médicale de Paris 1916;40:798-804. 11 Critchley M. The parietal lobes. London: Macmillan, 1953:

12 Bruns L. Uber Störungen der Gleichgewichtes bei Stirnhirntumoren. Disch Med Wochenschr 1892;18: 138-40.

13 Petras J. Connexions of the parietal lobe. $f$ Psychiatr Res 1971;8:189-201.

14 Chow KL. A retrograde cell degeneration study of the cortical projection field of the pulvinar in the monkey. $f$ Comp Neurol 1950;93:313-40.

15 Wiesendanger RM, Wiesendanger M, Ruegg DG. An anatomical investigation of the cortico-pontine projection in the primate (Macaca fascicularis and Saimiri sciureus) II: the projection from frontal and parietal association areas. Neuroscience 1979 4:747-65.

16 Pierrot-Deseilligny C, Gray F, Brunet P. Infarcts of both inferior parietal lobules with impairment of visually guided eye movements, peripheral visual inattention, and optic ataxia. Brain 1986;109:81-97.

17 Besta C. Sulla funzione della regione parietale dell'uomo. Rivista di Patologiea Nervosa e Mentali 1922;27:535-8.

18 Roussy G, Levy G. Troubles sensitivo-moteurs d'aspect radiculaire et troubles d'aspect cérébelleux par lésion radiculaire et troubles d'aspect céré
corticale. Rev Neurol 1926;2:376-89.

19 Foix C, Thévenard A. Syndromes pseudo-cérébelleux d'origine pariétale, bilatérale de la région paracentrale postérieure. Rev Neurol 1922;29:1502-4.

20 Alajouanine T, Lemaire A. Tumeur de la région paracentrale postérieure avec symptômes "pseudo-cérébelleux". Rev Neurol 1925;1:71-5.

21 Pause M, Freund HY. Role of the parietal cortex for sensorimotor transformation. Evidence from clinical observations. Brain Behav Evol 1989;33:136-40.

22 Pause M, Kunesh E, Binkofski F, Freund HJ. Sensorimotor disturbances with lesions of the parietal cortex. Brain 1989;112:1599-625. 